\title{
Efficiency Analysis of Scientific and Technological Innovation in Grain Production Based on Improved Grey Incidence Analysis
}

\author{
Shuhua Zhang ${ }^{1,2} \mathbb{D}$, Bingjun $\mathrm{Li}^{1, *(\mathbb{D})}$ and Yingjie Yang ${ }^{2}$ \\ 1 College of Information and Management Science, Henan Agricultural University, Zhengzhou 450046, China; \\ hnshzhang@163.com \\ 2 School of Computer Science and Informatics, Institute of Artificial Intelligence, De Montfort University, \\ The Gateway, Leicester LE1 9BH, UK; yyang@dmu.ac.uk \\ * Correspondence: zzlbjun@163.com; Tel.: +86-0371-63579615
}

check for updates

Citation: Zhang, S.; Li, B.; Yang, Y. Efficiency Analysis of Scientific and Technological Innovation in Grain Production Based on Improved Grey Incidence Analysis. Agriculture 2021, 11, 1241. https://doi.org/10.3390/ agriculture11121241

Academic Editor: Francesco Caracciolo

Received: 3 November 2021

Accepted: 2 December 2021

Published: 8 December 2021

Publisher's Note: MDPI stays neutral with regard to jurisdictional claims in published maps and institutional affiliations.

Copyright: (c) 2021 by the authors Licensee MDPI, Basel, Switzerland. This article is an open access article distributed under the terms and conditions of the Creative Commons Attribution (CC BY) license (https:// creativecommons.org/licenses/by/ $4.0 /)$.

\begin{abstract}
Analyzing and evaluating the efficiency of scientific and technological innovation in grain production is conducive to the rational allocation of resources, promoting the development of scientific and technological innovation in grain production and providing guarantee for grain security. By refining the elements of grain production and scientific and technological innovation, an evaluation system of scientific and technological innovation in grain production is constructed. Firstly, combining linear programming together with the traditional grey synthetic incidence analysis model, a incidence analysis of the scientific and technological innovation indicators of grain production is carried out, and the key and secondary indexes affecting grain outputs are screened by an improved grey incidence analysis model. Secondly, based on DEA-Malmquist index model and taking the grain production process as the research object, the scientific and technological achievement transformation indicators are divided into pre-production, in-production and post-production indicators. The key indicators and secondary indicators of scientific and technological innovation of grain production in various cities of Henan Province from 2010 to 2019 are used to analyze the efficiency of scientific and technological innovation in each stage of grain production. The results show that: (1) The type of basic ability of scientific and technological innovation indicators and the transformation ability of scientific and technological innovation achievements are the major indicators influencing grain outputs, and the investment of basic resources of scientific and technological innovation and the transformation of scientific and technological innovation achievements are the most important to improve grain outputs. (2) In addition, the study reveals that the secondary indicators of the technological innovation efficiency of grain production based on the DEA-Malmquist index model are more efficient than the key indicators in the pre-production, in-production and post-production stages. And there are gaps in the scientific and technological innovation performance of grain production among cities in Henan Province, and the index of technological progress is the leading factor for the gap.
\end{abstract}

Keywords: grey incidence analysis; DEA-Malmquist index model; grain production; scientific and technological innovation

\section{Introduction}

Grain production and grain security have always been important for maintaining national stability and security, and a major strategic component of governance [1]. The sudden outbreak and multiple challenges, such as floods, typhoons, diseases and insect pests, make grain security face many practical hidden dangers and new difficulties. Although agricultural development accounts for only a small proportion in the overall economy in China with less cultivated land per capita and the scarcity of fresh water its importance cannot be overestimated for China's development and prosperity. China's grain production 
is still facing the constraints of increasing production rate lower than consumption growth rate, increasing demands, resources and ecology. So how to firmly control the initiative of grain security is very important to resolve the challenge of international grain crisis. As a new idea of the central government to ensure grain production capacity and a new way of the 13th five-year plan, the policy of "grain storage in technology" provides a strong support for Henan Province to rely on technology to ensure grain security. The United Nations Food and Agriculture Organization (FAO) pointed out in the report that $80 \%$ of the growth of international grain production depends on the improvement of per unit area output, and $60-80 \%$ of the increase in per unit area output will come from the scientific and technological progress of grain seeds. To maximize the efficiency of technical innovation, it is necessary to identify and analyze the impact of continuous adjustment of agricultural production input factors on the efficiency of grain production technical innovation under the new situation of agricultural development, and explore the effective breakthrough point to further improve the efficiency of grain production.

Scientific and technological innovation in grain production refers to the continuous research and develop new technologies such as grain production breeding, cultivation and harvest under a certain innovation environment and social market economy. A series of processes by introducing new technologies and methods into grain production system, producing high-level scientific and technological innovation achievements, and improve grain production capacity and social benefits. Its foundation is agricultural scientific research, grain production technology is the link, high-tech industrialization is the feature, and the way is the combination of technological innovation and industrial development, which includes scientific research, education, promotion and other links. Agricultural scientific and technological innovation can not only be used as an endogenous driving force, but also optimize the resource elements, promote the transformation and upgrading of agriculture, realize the modernization of grain production, and take the road of modern agricultural development. How agricultural scientific and technological innovation can increase grain production and better guarantee grain security has become a hot focus of agricultural economic researchers, managers and policy makers at home and abroad. A lot of studies have been carried out from the perspectives of technical efficiency, contribution of scientific and technological progress, analysis of impact indicators and so on. Chinese scholar Yang Chuanxi [2] once pointed out that agricultural scientific and technological resources are an important factor to realize the transformation of agricultural development mode and sustainable development of agriculture. The development of modern agriculture also urgently needs to transform agricultural scientific and technological resources into real productivity. Based on the DEA model, many scholars established the input-output evaluation model of agricultural scientific and technological innovation, analyzed its input-output efficiency, so as to improve the development level of agricultural scientific and technological innovation and realize the sustainable development of agriculture [3-7]. Tang and Jose [8] used the Stochastic Frontier Analysis model (SFA) to measure the technical efficiency and changing trend of grain production. The results show that the contribution rate of technology in grain production is increasing. Zheng et al. [9] used DEA to analyze the rice production efficiency and constraints in China from 1995 to 2017, and found that the negative impact of excessive investment on rice production efficiency was greater than that of insufficient output. Shen et al. [10] used the fixed-effect panel regression model to calculate the degree of impact of agricultural technological innovation level on grain production benefits in China, and the results show that the improvement of agricultural technology innovation has a significant positive impact on grain outputs. Zayats and Samsonovich [11] pointed out that every stage of the development of agricultural production and the fundamental change of production technology in the Republic of Belarus is related to the achievements of scientific and technological progress. Chen et al. [12] calculated the agricultural total factor productivity of Gansu Province by DEA-Malmquist index model based on the total factor productivity analysis framework, identified the agricultural transformation stage based on the total factor productivity, and analyzed the evolution of agricultural devel- 
opment types. Based on the Stochastic Frontier model and Heckman Selection model, Shi et al. [13] calculated the technical efficiency, allocation efficiency and scale efficiency of rice production. By comparing and analyzing the influencing factors of three different stages of rice cultivation, they proposed to promote the mechanization in the chemical application stage of rice cultivation to improve the technical efficiency. Scientific and technological progress is the "first productive force" to consolidate grain production capacity and activate the vitality of grain production. Jiang et al. [14] constructed an improved multi-factor two-level CES production function, analyzed the speed and contribution of scientific and technological progress in grain production based on panel data, found that the speed and contribution of scientific and technological progress in grain production increased significantly before and after agricultural tax reduction, and found that the speed and contribution of scientific and technological progress in grain production in China showed significant spatial "differentiation". Based on China's agricultural regional panel data, Wang and Guo [15] systematically analyzed the fluctuation of total factor productivity growth and its decomposition conditions, and analyzed the relationship and the connotation among factor allocation efficiency, technological progress deviation and agricultural total factor productivity. Similarly, many scholars have analyzed the relevant influencing factors of scientific and technological innovation in grain production, which is helpful to achieve the realization of grain increase and security [16-18]. For example, Zhu et al. [19] put forward the countermeasures of agricultural scientific and technological innovation in China through comparative analysis of the modes of agricultural scientific and technological innovation in China and the United States. Li et al. [20] constructed a grain production index system from the aspects of natural factors, scientific and technological factors, social and economic factors and agricultural production conditions. They analyzed the fluctuation characteristics of grain outputs of by using HP filter, and comprehensively evaluated the influence degree of grain production fluctuation under various influencing factors in different periods by using grey incidence analysis and analytic hierarchy process. Liu and Liu [21], Dong et al. [22] have made use of grey models to analyze the level of agricultural science and technology, which provides technical basis for exploring the development of agricultural science and technology.

In terms of the evaluation methods, Data Envelopment Analysis (DEA), Stochastic Frontier Analysis, Statistical Regression Analysis, weighting method and index analysis are used to analyze the efficiency of scientific and technological innovation. Compared with other methods, DEA method can effectively evaluate a complex system with multiindex input and multi-index output. It has the characteristics of no weight assumption and no relationship expression. The process of scientific and technological innovation in grain production is a long-term multi-input and multi-output complex system. The traditional DEA model measures the static relative efficiency of different decision-making units in the same period, while the Malmquist index method measures the Malmquist total factor productivity index through the change of productivity from current period to next period. Therefore, the combination of Malmquist index and DEA can analyze the dynamic change of efficiency. DEA-Malmquist index model is also widely used in the evaluation of production efficiency in agriculture, industry, medical and other industries [19]. For example, $\mathrm{He}$ and $\mathrm{Li}$ [23] selected the relevant index data of provincial grain security from 2007 to 2015, tested and analyzed it based on Malmquist-DEA model, and found that the improvement of grain total factor productivity mainly came from technological progress. Zhao et al. [24] used DEA-Malmquist method to analyze and predict the development trend of driving factors of grain production, and concluded that technological progress is an important precursor factor to promote the improvement of grain production efficiency in Heilongiiang Province. Zhang et al. [25] used DEA-Malmquist index method to take three provinces of Northeastern China as an example, tested the relationship between agricultural technology progress, scale efficiency and the growth of grain production efficiency. And put forward policy suggestions such as increasing agricultural financial input and strengthening agricultural science and technology research and development. 
Scientific and technological innovation is an important factor to drive crop production. Clarifying the relationship between scientific and technological innovation and grain production is of great significance for promote the sustainable development of agriculture, leading and support the construction of modern agriculture, and formulating a reasonable development strategy of agricultural scientific and technological innovation. Existing literature has carried out a lot of beneficial research on agricultural scientific and technological innovation and grain production, but there are still some areas worthy of further exploration: The existing research focuses mostly on the efficiency of input index or transformation of achievement, without considering the classification of input index. And the process of scientific and technological innovation in grain production is also not studied in stages, and the transformation index of scientific and technological innovation achievements in each stage is not taken as the output index to analyze its efficiency. So the consideration of the each stage is necessary, to explore the internal relationship between grain production and scientific and technological innovation. Therefore, this paper constructs the index system of scientific and technological innovation of grain production with full consideration of their classification and efficiency in inputs and their contribution to outputs in each stage. Firstly, the key indexes and secondary indexes of grain production are screened out by the improved grey incidence analysis. Secondly, based on the DEA-Malmquist index model, the transformation index of scientific and technological achievements is divided into pre-production, in-production and post-production output index according to the grain production process. The efficiency of the key and secondary of input indexes and output index of each stage is analyzed. Taking Henan Province as an example, the efficiency of scientific and technological innovation in grain production is analyzed.

The structure of this paper is as follows: After the introduction, Section 2 provides research methods and the data sources of this research, and constructs the scientific and technological innovation system of grain production. Section 3 measures and analyzes the efficiency of scientific and technological innovation of grain production in Henan Province. Conclusions and future work will be discussed in Section 4 .

\section{Scientific and Technological Innovation System of Grain Production}

\subsection{Overview of Study Area}

Henan Province $\left(31^{\circ} 23^{\prime}-36^{\circ} 22^{\prime} \mathrm{N}, 110^{\circ} 21^{\prime}-116^{\circ} 39^{\prime}\right.$ E) is located in the central part of China. The terrain of Henan Province looks from north to south, connecting the east with the west, and the terrain is high in the west and low in the east. It is composed of plains, basins, mountains, hills and water surface. It crosses four water systems of Haihe River, Yellow River, Huaihe River and Yangtze River. A large part of Henan Province is located in the warm temperate zone, and the southern part is trans-subtropical, which belongs to the continental monsoon climate of transition from the northern subtropical zone to the warm temperate zone. It is suitable for the growth of various crops and is one of the main grain producing areas in China. Henan Province is divided into five regions: East Henan (Kaifeng, Shangqiu, Zhoukou), West Henan (Luoyang, Sanmenxia), North Henan (Anyang, Hebi, Xinxiang, Jiaozuo, Puyang, Jiyuan), South Henan (Nanyang, Xinyang, Zhumadian) and Central Henan (Zhengzhou, Pingdingshan, Xuchang, Luohe), including 18 cities, with different natural resources and scientific and technological innovation ability.

Since the early days of the People's Republic of China, especially after the Reform and Opening Up, Henan Province has made remarkable achievements in grain production (Reform and Opening Up is a policy put forward by China in 1978 to promote the development of national productive forces and speed up the modernization of the country). The grain output in Henan Province increased from $1900.00 \times 10^{7} \mathrm{~kg}$ in 1978 to $6695.36 \times 10^{7} \mathrm{~kg}$ in 2019. During these 42 years, the grain production and main production inputs in Henan Province showed periodic characteristics. As shown in Figure 1, 1978-1984 opened a new stage for the reform, and in 1982, the Central Committee issued the No.1 Document of the Central Committee with the household contract responsibility system as the main content 
for three consecutive years. The grain yield per unit area in Henan Province entered the stage of $3000.00 \mathrm{~kg} / \mathrm{ha}$, but the average grain yield per unit area during this period was only $2621.87 \mathrm{~kg} / \mathrm{ha}$, and the input of machinery and fertilizer was low, thus showing that Henan Province was in a stage of low production efficiency. 1985-2006 was a leap-forward stage, and in the mid-1980s, the reform of China's science and technology and other fields began, and it was proposed that science and technology is the primary productive forces, which pointed out the direction for mechanization and scientization of grain production. At this stage, great breakthroughs were made in the use of machinery and the input of chemical fertilizer, which increased from $1507.00 \times 10^{4} \mathrm{kw}$ and $140.16 \times 10^{7} \mathrm{~kg}$ in 1984 to $8309.10 \times 10^{4} \mathrm{kw}$ and $540.43 \times 10^{7} \mathrm{~kg}$ in 2006 , respectively, and the grain yield per unit area also entered the order of $5000.00 \mathrm{~kg} / \mathrm{ha}$. At this stage, the country implemented the parallel system of national ordering and market buying and selling, and the agricultural product price policy lowered the purchase price, which led to the farmers' drastic adjustment of planting structure, thus causing the fluctuation of grain output. During 2007-2019, it was a steady growth stage. Under the extensive income-increasing mode based on "quantity", grain production is faced with constraints such as cultivated land, water resources and ecological pollution. In 2007, the Central Committee of the Communist Party of China and the State Council first explicitly put forward the use of modern science and technology to transform agriculture. Since then, except in 2011, China has issued the Central Document No.1 with scientific and technological innovation to develop agriculture and speed up agricultural modernization as its main contents every year, which provides policy guidance for agriculture to achieve sustainable development based on scientific and technological progress. In the past 13 years, the grain output in Henan Province has increased from $5512.84 \times 10^{7} \mathrm{~kg} / \mathrm{ha}$ in 2007 to $6237.21 \times 10^{7} \mathrm{~kg} / \mathrm{ha}$ in 2019 , and the grain yield per unit area has successfully passed the $6000.00 \times 10^{7} \mathrm{~kg}$ mark.
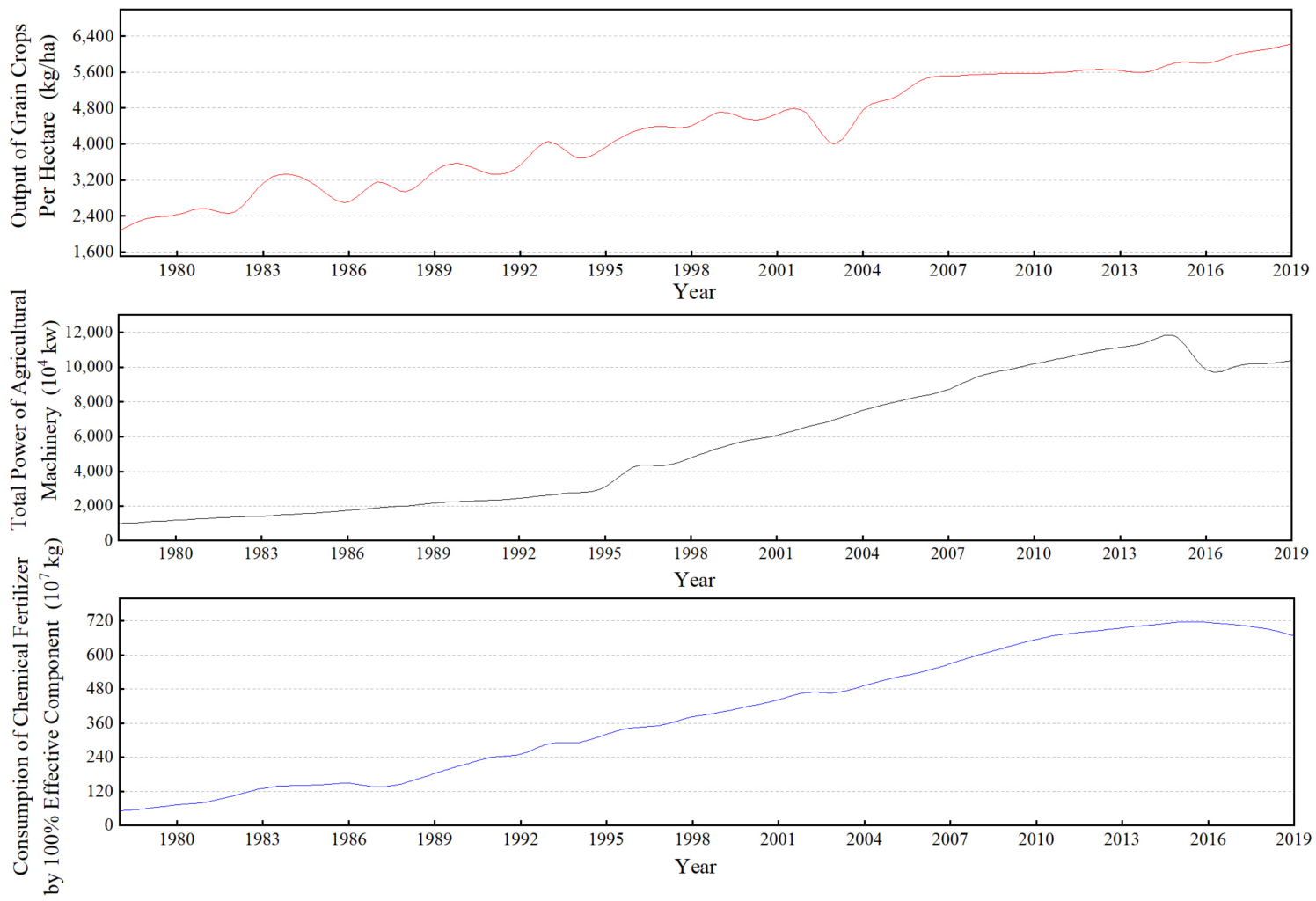

Figure 1. Trends of grain yield per unit area, total mechanical power and fertilizer input in Henan Province from 1978 to 2019 . 
From the historical perspective of the periodic development of grain output, grain output is closely related to scientific and technological innovation and development. Under the background of modern agricultural development, in 2019, the contribution rate of agricultural scientific and technological progress in Henan Province was 62\%, the comprehensive mechanization rate of farming and harvesting reached $69 \%$, and the utilization rate of chemical fertilizer was nearly $40 \%$. Agricultural scientific and technological innovation and development made a major breakthrough and made outstanding contributions to agricultural development. However, the overall contribution rate of agricultural science and technology innovation is still far lower than that of agricultural technology powers. For example, in developed countries, the contribution rate of agricultural science and technology in the United States is over $80 \%$, while that in Britain and Germany is over $90 \%$. In order to ensure the steady growth of grain output in the future and ensure food security, we should conduct an in-depth study on the efficiency of scientific and technological innovation in grain production. Therefore, this study takes the cities and the whole province of Henan Province as the decision-making units, and puts forward the scientific and technological innovation system of grain production, which provides the basis for further exploring the situation of the cities in Henan Province in the efficiency of scientific and technological innovation of grain production.

\subsection{Materials and Methods}

Based on DEA-Malmquist index model, it is necessary to determine the input and output indicators to measure the efficiency of scientific and technological innovation in grain production. In order to explore the input and output efficiency of agricultural scientific and technological innovation in grain production, following the basic principles of purposiveness, comprehensiveness, operability, comparability, quantitative and qualitative combination, the indicators of economy, manpower, infrastructure, funds, policy and educational environment, scientific and technological achievements are selected as input indicators. In the aspect of selecting output index, different from the traditional research, since the secondary index is still an indispensable technical index for the scientific and technological innovation of grain production, we not only study the key index inputoutput efficiency of the scientific and technological innovation of grain production, but also try to explore the secondary index input-output efficiency of scientific and technological innovation of grain production. The key input indicators and secondary input indicators are selected by using the improved grey incidence analysis method, and the transformation indicators of scientific and technological achievements are divided into pre-production, in-production and post-production indicators according to the grain production. Based on the DEA-Malmquist index model, the scientific and technological innovation efficiency of grain production in Henan Province is evaluated. The specific process is shown in Figure 2.

\begin{tabular}{|c|c|c|}
\hline $\begin{array}{c}\text { Input in scientific and } \\
\text { technologIcal innovation } \\
\text { for grain production }\end{array}$ & The evaluation unit & $\begin{array}{c}\text { Output in scientific and } \\
\text { technologIcal innovation } \\
\text { for grain production }\end{array}$ \\
\hline Key indicators & $\begin{array}{c}\text { Cities in } \\
\text { Henan }\end{array}$ & $\begin{array}{c}\text { Indicators of scientific and } \\
\text { technological innovation in } \\
\text { pre-production grain }\end{array}$ \\
\hline Province & $\begin{array}{c}\text { Indicators of scientific and } \\
\text { technological innovation in } \\
\text { in-production of grain }\end{array}$ \\
\hline Secondary indicators & $\begin{array}{c}\text { Indicators of scientific and } \\
\text { technological innovation in } \\
\text { post-production of grain }\end{array}$ \\
\hline
\end{tabular}

Figure 2. Conceptual framework of grain production scientific and technological innovation efficiency evaluation. 
The data of this study are derived from 2010-2019 Henan scientific and technological statistical yearbook, Henan statistical yearbook, annual public work reports of Ministry of industry and information technology of the people's Republic of China, Ministry of agriculture and rural areas of China, and Brink agricultural data terminal. The system of scientific and technological innovation in grain production is divided into four types: Basic ability type, technological innovation environment and production capacity type, research capability type and transformation ability type, including 9 first-level indicators and 22 second-level indicators, as shown in Table 1.

Table 1. Evaluation index system of scientific and technological innovation in grain production.

\begin{tabular}{|c|c|c|c|}
\hline Type & First Level Indicators & Secondary Indicators & Index Explanation \\
\hline \multirow{5}{*}{$\begin{array}{l}\text { Basic ability of scientific } \\
\text { and technological } \\
\text { innovation in } \\
\text { grain production }\end{array}$} & Economic level & $\begin{array}{l}\text { Gross domestic product } x_{1} \\
\text { Total financial revenue } x_{2}\end{array}$ & $\begin{array}{l}\text { Gross domestic product level } \\
\text { Fiscal revenue level }\end{array}$ \\
\hline & Human resources & R\&D personnel $x_{3}$ & Number of researchers \\
\hline & \multirow[t]{2}{*}{ Infrastructure } & $\begin{array}{c}\text { Number of organization for R\&D } x_{4} \\
\text { Number of R\&D units } x_{5} \\
\text { Average number of fixed and mobile } \\
\text { phone users } x_{6} \\
\text { Length of highways } x_{7}\end{array}$ & $\begin{array}{c}\text { Organizational structure of scientific } \\
\text { and technological innovation } \\
\text { Information and communication } \\
\text { technology penetration rate } \\
\text { Transportation infrastructure }\end{array}$ \\
\hline & & $\begin{array}{c}\text { Expenditure on scientific and } \\
\text { technological instruments and } \\
\text { equipment } x_{8}\end{array}$ & $\begin{array}{c}\text { Scientific and } \\
\text { technological infrastructure }\end{array}$ \\
\hline & Capital investment & $\begin{array}{c}\text { Internal expenditures on R\&D } x_{9} \\
\text { Government funds of expenditures } x_{10}\end{array}$ & $\begin{array}{l}\text { Funds for scientific and } \\
\text { technological innovation } \\
\text { Government financial support }\end{array}$ \\
\hline \multirow{3}{*}{$\begin{array}{l}\text { Technological innovation } \\
\text { environment and } \\
\text { production capacity of } \\
\text { grain production }\end{array}$} & Policy environment & $\begin{array}{l}\text { Information quantity of government } \\
\text { policies and regulations } x_{11}\end{array}$ & Policy support \\
\hline & $\begin{array}{l}\text { Educational } \\
\text { environment }\end{array}$ & Educational funds $x_{12}$ & Educational level \\
\hline & Productivity level & Grain outputs per unit area $x_{13}$ & Grain land productivity \\
\hline $\begin{array}{l}\text { Research capability of } \\
\text { scientific and } \\
\text { technological innovation } \\
\text { in grain production }\end{array}$ & $\begin{array}{l}\text { Scientific and } \\
\text { technological } \\
\text { achievements }\end{array}$ & $\begin{array}{c}\text { Project of R\&D } x_{14} \\
\text { Scientific papers published } x_{15} \\
\text { Number of scientific and technological } \\
\text { patents } x_{16}\end{array}$ & $\begin{array}{l}\text { Basic research achievements of } \\
\text { scientific and } \\
\text { technological innovation } \\
\text { Research achievements in the } \\
\text { application of scientific and } \\
\text { technological innovation }\end{array}$ \\
\hline $\begin{array}{l}\text { Transformation ability of } \\
\text { scientific and } \\
\text { technological innovation } \\
\text { achievements in } \\
\text { grain production }\end{array}$ & $\begin{array}{l}\text { Transformation of } \\
\text { scientific and } \\
\text { technological } \\
\text { achievements }\end{array}$ & $\begin{array}{c}\text { Seed consumption } x_{17} \\
\text { Number of tillage machines } x_{18} \\
\text { Water-saving irrigation machinery } x_{19} \\
\text { Consumption of chemical fertilizer by } \\
100 \% \text { effective component } x_{20} \\
\text { Use of agricultural pesticide } x_{21} \\
\text { Number of combine harvesters } x_{22}\end{array}$ & $\begin{array}{c}\text { Transformation degree of breeding } \\
\text { technology achievements } \\
\text { Achievement transformation of } \\
\text { cultivation and sowing technology } \\
\text { Transformation degree of irrigation } \\
\text { technology achievements } \\
\text { Transformation degree of fertilization } \\
\text { technology achievements } \\
\text { Transformation degree of pest } \\
\text { technology achievements } \\
\text { Transformation degree of harvest } \\
\text { technology achievements }\end{array}$ \\
\hline
\end{tabular}

Note: Due to grain production, scientific and technological innovation of incomplete information and uncertain situation is widespread, it is a complex system process in which part of the information is known and part of the information is unknown, and a small amount of incomplete data is inevitable, and because of the grey prediction model has the characteristics of small sample, simple operation and high precision in short-term prediction, it is necessary to deal with the incomplete data. The mean value method is used for the middle value, and GM $(1,1)$ is used for the end data.

\subsection{Research Methods}

\subsubsection{Improved Grey Incidence Analysis}

The methods of comprehensive evaluation methods mainly include Principal Component Analysis [26], Factor Analysis [27] and Grey Incidence Analysis [28]. The principal component analysis method is associated with a number of limitations. It usually involves a certain fuzziness in explaining the meaning of the principal component (not as complete as the original sample), the principal component with small contribution rate may contain important information about the sample difference, and whether the orthogonal vector space of its eigenvalue matrix is unique. The factor analysis method needs large enough 
sample size, the original variables must have correlation and the generated common factors must have practical significance. These assumptions may not apply in some real world applications. Compared with these methods, grey incidence analysis is not restricted by these problems. The essence of the grey incidence analysis method is to analyze whether the relationship between different sequences is close, and distinguish them by the geometric similarity of data sequence curves. The closer the degree of grey incidence between the reference sequence and the comparison sequence is to 1 , the closer the geometric shape of the corresponding sequence is. The closer the relationship is, the greater the relational degree is. That is to say, the sequence comparison is a significant indicator affecting the development evaluation of the system. Many scholars have done in-depth research on grey incidence analysis, and various types of models have been developed, some of which can be seen in the literature [29-31]. The basic idea of the traditional grey incidence analysis is to judge the geometric similarity of the development trends of various sequences according to the absolute value of the difference between the observed values of the series, ignoring the proximity of the observation values [32]. In the traditional grey synthetic incidence analysis method, the combination coefficient is often determined by subjective experience, preference or average weighted method, which is lack of scientific rigor. At present, the methods to determine the weight of each index in the system mainly include subjective weighting method, objective weighting method and intelligent weighting method by using intelligent algorithms to calculate through big data mining [33]. However, these three weighting methods all have their advantages and disadvantages. The subjective weighting method commonly includes analytic hierarchy process (AHP) [34], Delphi method [35], etc., the objective weighting method mainly includes principal component analysis [34], coefficient of variation [36], entropy method [36], TOPSIS method [37], etc., and the intelligent weighting method includes BP neural network [38], etc. However, due to the different mechanisms of weighting methods and the different ways of weight assignment, there will be differences in the evaluation conclusions among various evaluation methods in applications. Based on the characteristics of grain production scientific and technological innovation index data, such as large difference in order of magnitude, zero value in original data and periodicity, this paper proposes an analysis method based on synthetic degree of grey incidence with linear programming, which combines the geometric similarity of feature vector and the similarity of change rate. The specific steps are as follows:

The representation of basic degree of grey incidence set. There are $f$ methods to determine the relational degree of each index and behavior feature sequence in the system, and then $f$ degree of grey incidence vectors $\gamma_{j}=\left[\gamma_{j 1}, \gamma_{j 2}, \ldots, \gamma_{j l}\right], j=1,2, \ldots, f$ can be obtained. Among them, $l$ is the total number of grain production technology innovation indexes. In order to ensure the normalization of combination coefficient value, the degree of grey incidence vector $\gamma_{k}$ is normalized. Therefore, the basic degree of grey incidence set is $E=\left\{\gamma_{1}^{\prime}, \gamma_{2}^{\prime}, \ldots, \gamma_{f}^{\prime}\right\}$, and any linear combination of $f$ degree of grey incidence vectors can be expressed as follows:

$$
\Gamma=\sum_{j=1}^{f} \omega_{j}^{*} \gamma_{j}^{\prime T} .
$$

where $\omega_{k}>0$ is the combination coefficient of degree of grey incidence.

1. Calculate the degree of grey incidence. Based on the above introduction and research needs, this study selects the grey absolute incidence analysis method and grey relative incidence analysis method:

(1) The characteristic matrix is constructed. Let the system reference sequence $X_{0}=\left(x_{0}(1), x_{0}(2), \ldots, x_{0}(n)\right)$ and the $i$-th comparison sequence in the sample set be $X_{i}=\left(x_{i}(1), x_{i}(2), \ldots, x_{i}(n)\right), i=1,2, \ldots, n$.

(2) Absolute degree of grey incidence 
The zero image of the starting point of the sequence is obtained as:

$$
\begin{aligned}
X_{0}^{0} & =\left(x_{0}^{0}(1), x_{0}^{0}(2), \ldots, x_{0}^{0}(n)\right)=\left(0, x_{0}(2)-x_{0}(1), \ldots, x_{0}^{0}(n)-x_{0}(1)\right), \\
X_{i}^{0} & =\left(x_{i}^{0}(1), x_{i}^{0}(2), \ldots, x_{i}^{0}(n)\right)=\left(0, x_{i}(2)-x_{i}(1), \ldots, x_{i}^{0}(n)-x_{i}(1)\right) .
\end{aligned}
$$

For the value of $\left|s_{0}\right|,\left|s_{i}\right|,\left|s_{i}-s_{0}\right|$

$$
\begin{gathered}
\left|s_{0}\right|=\left|\sum_{k=2}^{n-1} x_{0}^{0}(k)+\frac{1}{2} x_{0}^{0}(n)\right|, \\
\left|s_{i}\right|=\left|\sum_{k=2}^{n-1} x_{i}^{0}(k)+\frac{1}{2} x_{i}^{0}(n)\right|, \\
\left|s_{i}-s_{0}\right|=\left|\sum_{k=2}^{n-1}\left(x_{i}^{0}(k)-x_{0}^{0}(k)\right)+\frac{1}{2}\left(x_{i}^{0}(n)-x_{0}^{0}(n)\right)\right| .
\end{gathered}
$$

where, $s_{i}-s_{0}=\int_{1}^{n}\left(X_{i}^{0}-X_{0}^{0}\right) d t$.

Calculate the absolute degree of grey incidence:

$$
\gamma_{1}=\frac{1+\left|s_{0}\right|+\left|s_{i}\right|}{1+\left|s_{0}\right|+\left|s_{i}\right|+\left|s_{i}-s_{0}\right|} .
$$

(3) Calculation of relative degree of grey incidence

The initial image of the sequences are as follows:

$X^{\prime}{ }_{0}=\frac{X_{0}}{x_{0}(1)}=\left(\frac{x_{0}(1)}{x_{0}(1)}, \frac{x_{0}(2)}{x_{0}(1)}, \ldots, \frac{x_{0}(n)}{x_{0}(1)}\right), X_{i}^{\prime}=\frac{X_{i}}{x_{i}(1)}=\left(\frac{x_{i}(1)}{x_{i}(1)}, \frac{x_{i}(2)}{x_{i}(1)}, \ldots, \frac{x_{i}(n)}{x_{i}(1)}\right)$.

For the value of $\left|s^{\prime}{ }_{0}\right|,\left|s^{\prime}{ }_{i}\right|,\left|s_{i}^{\prime}-s^{\prime}{ }_{0}\right|$

$$
\begin{gathered}
\left|s^{\prime}{ }_{0}\right|=\left|\sum_{k=2}^{n-1} x_{0}^{\prime 0}(k)+\frac{1}{2} x_{0}^{\prime 0}(n)\right|, \\
\left|s^{\prime}{ }_{i}\right|=\left|\sum_{k=2}^{n-1} x_{i}^{\prime 0}(k)+\frac{1}{2} x_{i}^{\prime 0}(n)\right|, \\
\left|s_{i}^{\prime}-s_{0}^{\prime}\right|=\left|\sum_{k=2}^{n-1}\left(x_{i}^{\prime 0}(k)-x_{0}^{\prime 0}(k)\right)+\frac{1}{2}\left(x_{i}^{\prime 0}(n)-x_{0}^{\prime 0}(n)\right)\right| .
\end{gathered}
$$

where, $s_{i}-s^{\prime}{ }_{0}=\int_{1}^{n}\left(X^{\prime 0}-X^{\prime 0}\right) d t$.

Calculate the relative degree of grey incidence:

$$
\gamma_{2}=\frac{1+\left|s_{0}^{\prime}\right|+\left|s_{i}^{\prime}\right|}{1+\left|s^{\prime}{ }_{0}\right|+\left|s_{i}^{\prime}\right|+\left|s_{i}^{\prime}-s^{\prime}{ }_{0}\right|} \text {. }
$$

(4) Normalize the degree of grey incidence vector $\gamma_{k}$, and the basic degree of grey incidence set can be obtained as $E=\left\{\gamma_{1}^{\prime}, \gamma_{2}^{\prime}\right\}$.

2. Optimized combination coefficient [39]. By optimizing $\omega_{j}$, the deviation between $\gamma^{\prime}$ and $\omega_{j}$ is minimized. Therefore, the optimal degree of grey incidence vector model can be obtained:

$$
\min \left\|\sum_{j=1}^{f} \omega_{j} \gamma_{j}^{\prime T}-\gamma_{g}^{\prime T}\right\|^{2},(g=1,2, \ldots, f) .
$$


Through the properties of matrix, the optimal first derivative of Equation (2) can be obtained under the following conditions:

$$
\sum_{j=1}^{f} \omega_{j} \gamma_{g}^{\prime} \gamma_{j}^{\prime T}=\omega_{g} \omega_{g}^{T},(g=1,2, \ldots, f)
$$

The matrix expression of the corresponding linear equations is as follows:

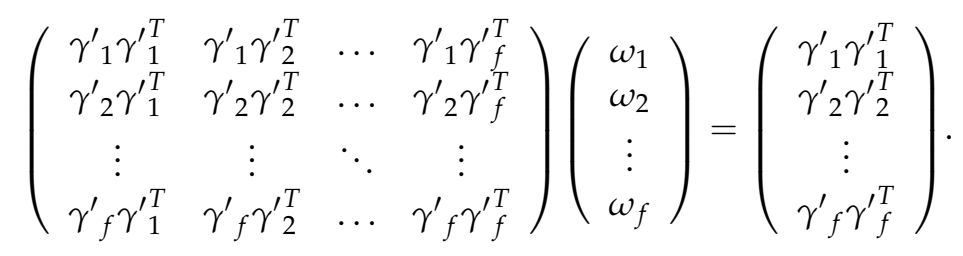

3. $\omega_{1}, \omega_{2}, \ldots, \omega_{f}$ can be obtained by Formula (4), and the degree of incidence combination coefficient $\omega_{j}$ is normalized:

$$
\omega^{*}=\frac{\omega_{j}}{\sum_{j=1}^{f} \omega_{j}} .
$$

Then the combination degree of incidence is

$$
\xi=\sum_{j=1}^{f} \omega_{j}^{*} \gamma_{j}^{T} .
$$

\subsubsection{DEA-Malmquist Index Model}

Malmquist index method was proposed by MALMQUIST [40], and then combined with DEA theory to build a DEA Malmquist index model. The model has the characteristics of no need to set strict premise assumptions, low requirements for data types, and capacity in handling different dimensions of input-output data. It has been widely used in agriculture, industry, finance, medical and other aspects. The formula is as follows [41]:

$$
\begin{gathered}
M_{0}^{t}=D_{0}^{t}\left(x^{t+1}, y^{t+1}\right) / D_{0}^{t}\left(x^{t}, y^{t}\right) \\
M_{0}^{t+1}=D_{0}^{t+1}\left(x^{t+1}, y^{t+1}\right) / D_{0}^{t}\left(x^{t}, y^{t}\right) \\
T f p c h=M_{0}=\left(M_{0}^{t} \times M_{0}^{t+1}\right)^{\frac{1}{2}}=E f f c h \times \text { Techch }=\text { Pech } \times \text { Sech } \times \text { Techch }
\end{gathered}
$$

In Equations (15)-(17), $x^{t}$ and $x^{t+1}$ are the inputs in periods $t$ and $t+1$ respectively, $y^{t}$ and $y^{t+1}$ are the outputs in periods $t$ and $t+1$ respectively, $M_{0}^{t}$ is the change of technical efficiency from $t$ to $t+1$ under the technical condition of time $t$, and $M_{0}^{t+1}$ is the change of technical efficiency under the technical condition of time $t+1 . D_{0}^{t}$ and $D_{0}^{t+1}$ are the production distance functions of $t$ and $t+1$ periods respectively, which represent the ratio between the actual value of total factor productivity in $t$ and $t+1$ periods and the frontier production surface respectively. The larger the value is, the closer the actual production is to the frontier production surface. Tfpch is the total factor productivity index, Techch is the technical efficiency change (representing the change of the frontier production surface), Effch is the technological efficiency change index (representing the catch-up situation of the frontier production surface), Pech is the pure technical efficiency change index, Sech is the scale efficiency change index.

When the value of Tfpch is greater than 1 , it means that the total factor productivity of grain production scientific and technological innovation is improved, and the technical conditions of production are improved, while when it is less than 1 , the opposite is true. 
When Techch index is greater than 1, it indicates the technological progress of scientific and technological innovation in grain production, otherwise, it is backward. When the Pech and Sech index are greater than 1, it means that the pure technical efficiency and scale efficiency of scientific and technological innovation in grain production are improved, and the degree of change can directly reflect their respective influence of the corresponding technical efficiency changes.

\section{Analysis on the Efficiency of Scientific and Technological Innovation of Grain Outputs in Henan Province}

\subsection{Grey Incidence Analysis of Evaluation Index and Grain Outputs}

In this paper, the seventh edition of grey modeling software is used to analyze the technological innovation indicators of grain production in Henan Province from 2010 to 2019 , the degree of incidence and order of incidence of the scientific and technological innovation indexes of grain production in Henan Province are obtained, and the key indicators and secondary indicators are selected. Based on the Formulas (1)-(14), the improved grey incidence coefficient between technological innovation index of grain production and grain outputs in Henan Province is calculated and analyzed, as follows:

(1) Substituting the statistical data into the Formulas (2)-(9), the relative degree of incidence and absolute degree of incidence can be calculated respectively as follows:

$\gamma_{1}=[0.6255,0.5937,0.6382,0.5950,0.6369,0.6537,0.8664,0.7011,0.6722,0.8056,0.6095,0.5736,0.6516,0.6827,0.6891,0.7927,0.6717$, $0.7761,0.8936,0.8001,0.8250,0.6436,0.6240,0.9370,0.7323,0.5375,0.7746,0.9144,0.7268,0.8374,0.6643,0.6405\}$.

$\gamma_{2}=[0.5228,0.6642,0.5040,0.5942,0.5347,0.5122,0.5909,0.9856,0.5104,0.5785,0.5014,0.5001,0.5020,0.5218,0.6301,0.5031,0.5003$, $0.6686,0.5006,0.5023,0.6996,0.5002,0.5212,0.5624,0.9622,0.5276,0.5050,0.5022,0.5115,0.5305,0.5001,0.5048\}$.

(2) After normalizing $\gamma_{1}$ and $\gamma_{2}$ and substituting them into Equations (10)-(14), the combined degree of incidence can be calculated by MATLAB software (The MathWorks, Natick, MA, USA) as follows:

$\xi=[0.5981,0.6215,0.6008,0.6000,0.6097,0.6141,0.7857,0.7985,0.6263,0.7399,0.5802,0.5551,0.6094,0.6371,0.6763,0.7069,0.6227$, $0.7485,0.7755,0.7117,0.7921,0.6033,0.5965,0.8252,0.8124,0.5391,0.6950,0.7903,0.6642,0.7464,0.6175,0.6026\}$.

According to the sorting of the degree of incidence of scientific and technological innovation indicators of grain production in Henan Province (Table 2). From the results of the degree of grey incidence and the order of incidence, in the comparative analysis of the two methods, the largest degree of grey incidence with grain outputs is the number of $R \& D$ units. The index ranking of the two methods after the number of tillage machines index has little difference, which has a certain consistency. However, there are obvious differences between the two methods in the order before the tillage machinery index, and the obvious differences are the grain outputs per unit area index and the total financial revenue index. The order of incidence of grain outputs per unit area is the third for the improved model and the sixth for the traditional model. Grain outputs per unit area determines the level of grain production and has a significant impact on the grain yield. The the degree of incidence of fiscal revenue indicators is the sixth for the improved model and the ninth for the traditional model. There is a big difference between the two indexes in the order of incidence of the two methods. As for the grain outputs per unit area index, it directly determines the level of grain production, and has a significant impact on grain yield. In terms of total fiscal revenue index, the fiscal revenue increased from 138.132 billion yuan in 2010 to 404.189 billion yuan in 2019 , with an average annual growth rate of $12.67 \%$. Since the fourth session of the 13th National People's Congress, the Ministry of Finance and other relevant departments have continuously increased support for grain production and strengthened the construction of grain planting bases, it can be seen that fiscal revenue is the key factor to ensure grain production. It can be seen that the improved grey incidence analysis model is more consistent with the actual situation of grain production in Henan Province, and the improved model can obtain more reliable results by calculating its weights through linear programming. 
Table 2. Degree of incidence and order of incidence of scientific and technological innovation index of grain production.

\begin{tabular}{|c|c|c|c|c|c|c|c|c|c|}
\hline \multirow[t]{2}{*}{ Index } & \multicolumn{2}{|c|}{$\begin{array}{l}\text { Improved Grey } \\
\text { Incidence Analysis }\end{array}$} & \multicolumn{2}{|c|}{$\begin{array}{l}\text { Traditional Grey } \\
\text { Incidence Analysis }\end{array}$} & \multirow[t]{2}{*}{ Index } & \multicolumn{2}{|c|}{$\begin{array}{l}\text { Improved Grey } \\
\text { Incidence Analysis }\end{array}$} & \multicolumn{2}{|c|}{$\begin{array}{l}\text { Traditional Grey } \\
\text { Incidence Analysis }\end{array}$} \\
\hline & $\begin{array}{l}\text { Degree } \\
\text { of Inci- } \\
\text { dence }\end{array}$ & $\begin{array}{c}\text { Order of } \\
\text { Inci- } \\
\text { dence }\end{array}$ & $\begin{array}{l}\text { Degree } \\
\text { of Inci- } \\
\text { dence }\end{array}$ & $\begin{array}{c}\text { Order of } \\
\text { Inci- } \\
\text { dence }\end{array}$ & & $\begin{array}{l}\text { Degree } \\
\text { of Inci- } \\
\text { dence }\end{array}$ & $\begin{array}{l}\text { Order of } \\
\text { Inci- } \\
\text { dence }\end{array}$ & $\begin{array}{l}\text { Degree } \\
\text { of Inci- } \\
\text { dence }\end{array}$ & $\begin{array}{c}\text { Order of } \\
\text { Inci- } \\
\text { dence }\end{array}$ \\
\hline $\begin{array}{l}\text { Number of } \\
\text { organization } \\
\text { for R\&D }\end{array}$ & 0.8794 & 1 & 0.8434 & 1 & Length of highways & 0.6118 & 12 & 0.6494 & 10 \\
\hline $\begin{array}{l}\text { Educational } \\
\text { funds }\end{array}$ & 0.7699 & 2 & 0.7328 & 3 & $\begin{array}{c}\text { Number of } \\
\text { tillage machines } \\
\text { Information quantity }\end{array}$ & 0.5919 & 13 & 0.6191 & 13 \\
\hline $\begin{array}{l}\text { Grain outputs } \\
\text { per unit area }\end{array}$ & 0.7087 & 3 & 0.7223 & 6 & $\begin{array}{l}\text { of government } \\
\text { policies and } \\
\text { regulations }\end{array}$ & 0.5819 & 14 & 0.6022 & 14 \\
\hline $\begin{array}{l}\text { Scientific } \\
\text { papers } \\
\text { published }\end{array}$ & 0.7023 & 4 & 0.7497 & 2 & $\begin{array}{l}\text { Average number of } \\
\text { fixed and mobile } \\
\text { phone users }\end{array}$ & 0.5708 & 15 & 0.5913 & 15 \\
\hline $\begin{array}{l}\text { Number of } \\
\text { R\&D units }\end{array}$ & 0.6938 & 5 & 0.7287 & 4 & $\begin{array}{l}\text { Government funds } \\
\text { of expenditures }\end{array}$ & 0.5644 & 16 & 0.5821 & 16 \\
\hline $\begin{array}{l}\text { Total financial } \\
\text { revenue }\end{array}$ & 0.6759 & 6 & 0.6566 & 9 & $\begin{array}{l}\text { Gross domestic } \\
\text { product }\end{array}$ & 0.5611 & 17 & 0.5741 & 17 \\
\hline $\begin{array}{c}\text { Seed } \\
\text { consumption }\end{array}$ & 0.6753 & 7 & 0.7236 & 5 & Project of R\&D & 0.5596 & 18 & 0.5726 & 18 \\
\hline $\begin{array}{l}\text { Consumption } \\
\text { of chemical } \\
\text { fertilizer by } \\
100 \% \text { effective } \\
\text { component }\end{array}$ & 0.6451 & 8 & 0.6839 & 7 & R\&D personnel & 0.5555 & 19 & 0.5723 & 19 \\
\hline $\begin{array}{c}\text { Internal } \\
\text { expenditures } \\
\text { on R\&D funds }\end{array}$ & 0.6410 & 9 & 0.6274 & 11 & $\begin{array}{l}\text { Expenditure on } \\
\text { scientific and } \\
\text { technological } \\
\text { instruments and } \\
\text { equipment }\end{array}$ & 0.5525 & 20 & 0.564 & 21 \\
\hline $\begin{array}{l}\text { Water-saving } \\
\text { irrigation } \\
\text { machinery }\end{array}$ & 0.6258 & 10 & 0.6675 & 8 & $\begin{array}{l}\text { Number of } \\
\text { combine harvesters }\end{array}$ & 0.5516 & 21 & 0.5678 & 20 \\
\hline $\begin{array}{l}\text { Use of } \\
\text { agricultural } \\
\text { pesticide }\end{array}$ & 0.6124 & 11 & 0.6229 & 12 & $\begin{array}{l}\text { Number of scientific } \\
\text { and technological } \\
\text { patents }\end{array}$ & 0.5313 & 22 & 0.5326 & 22 \\
\hline
\end{tabular}

It can be seen that the degree of incidence processed by the above formula is greater than 0.5 , and each index has a good correlation with grain outputs. Therefore, combined with the situation of scientific and technological innovation of grain production, the index above 0.6 is selected as the key influencing factor, and any index below 0.6 is the considered as secondary indexes. That is to say, the number of organization for R\&D, educational funds, grain outputs per unit area, scientific papers published, number of R\&D units, total financial revenue, seed consumption, consumption of chemical fertilizer by $100 \%$ effective component, internal expenditures on R\&D funds, water-saving irrigation machinery, use of agricultural pesticide, length of highways are selected as the key indicators, and the number of tillage machines and other indicators are selected as the secondary indicators. Among them, the type of basic ability indicators occupy the majority, the type of transformation ability indicators take the second place, the types of technological innovation environment and production capacity indicators and research capability indicators occupy the least number, which are 2 and 1 respectively. Among the four types of indicators, the key ones account for $1 / 2,1 / 3,1 / 3$ and $5 / 6$ of the corresponding indicator types respectively. It reflects that the type of transformation ability indicators, the types of basic ability indicators are closely related to the grain outputs. Increasing the input of basic resources of scientific and technological innovation and the transformation of scientific and technological innovation achievements are the key to improve the grain outputs.

\subsection{Measurement and Result Analysis of Scientific and Technological Innovation Efficiency of Grain Production in Henan Province}

In order to analyze the input-output efficiency of scientific and technological innovation in each stage of grain production, this paper takes the grain production process of 
Henan Province as the object, and divides the type of transformation ability indicators into pre-production, in-production and post-production indicators. Among them, the preproduction index is the seed consumption, the in-production index includes the number of tillage machines, the number of water-saving irrigation machines, consumption of chemical fertilizer by $100 \%$ effective component, and the post-production index is the number of combine harvesters. Through the key indicators and secondary indicators screened with the improved grey incidence model above (excluding the type of transformation ability indicators), DEA-Malmquist index model is used to analyze the efficiency of grain production in various stages of Henan Province. The calculation results are shown in Tables 3-5.

Table 3. Input-output efficiency of key indicators, secondary indicators and pre-production indicators of scientific and technological innovation of grain production in Henan Province.

\begin{tabular}{|c|c|c|c|c|c|c|}
\hline \multirow{2}{*}{ Province and Cities } & \multicolumn{3}{|c|}{ Key Indicators } & \multicolumn{3}{|c|}{ Secondary Indicators } \\
\hline & Effch & Techch & Tfpch & Effch & Techch & Tfpch \\
\hline Zhengzhou & 0.972 & 1.013 & 0.984 & 0.975 & 1.018 & 0.992 \\
\hline Kaifeng & 1.005 & 0.994 & 1.000 & 1.005 & 0.968 & 0.973 \\
\hline Luoyang & 0.988 & 0.985 & 0.973 & 0.981 & 1.033 & 1.013 \\
\hline Pingdingshan & 0.999 & 0.974 & 0.973 & 1.012 & 0.990 & 1.002 \\
\hline Anyang & 0.997 & 0.975 & 0.972 & 1.012 & 1.007 & 1.019 \\
\hline Hebi & 1.001 & 0.994 & 0.994 & 1.050 & 1.006 & 1.056 \\
\hline Xinxiang & 1.016 & 0.989 & 1.004 & 1.009 & 0.988 & 0.998 \\
\hline Jiaozuo & 0.995 & 1.002 & 0.997 & 0.993 & 1.001 & 0.994 \\
\hline Puyang & 1.001 & 1.017 & 1.018 & 1.038 & 0.962 & 0.998 \\
\hline Xuchang & 0.997 & 0.983 & 0.980 & 0.990 & 1.009 & 0.999 \\
\hline Luohe & 1.000 & 0.999 & 0.999 & 1.014 & 1.004 & 1.018 \\
\hline Sanmenxia & 0.973 & 0.949 & 0.923 & 1.103 & 0.942 & 1.038 \\
\hline Nanyang & 0.998 & 0.988 & 0.986 & 1.002 & 1.033 & 1.035 \\
\hline Shangqiu & 0.995 & 0.951 & 0.947 & 0.984 & 0.947 & 0.932 \\
\hline Xinyang & 1.000 & 1.049 & 1.049 & 0.957 & 0.893 & 0.854 \\
\hline Zhoukou & 1.000 & 0.992 & 0.992 & 1.000 & 1.063 & 1.063 \\
\hline Zhumadian & 1.000 & 0.949 & 0.949 & 1.000 & 0.973 & 0.973 \\
\hline Jiyuan & 0.992 & 0.995 & 0.987 & 1.006 & 0.984 & 0.990 \\
\hline Henan & 1.000 & 0.960 & 0.960 & 1.000 & 1.009 & 1.009 \\
\hline Mean & 0.996 & 0.987 & 0.983 & 1.006 & 0.990 & 0.997 \\
\hline
\end{tabular}

Breeding technology is the main index of scientific and technological innovation in the pre-production stage of grain production, and germplasm is the "chip" of grain production. Whether we can master the breeding technology and production technology of seeds well, and whether we can spread high-quality varieties to the fields is related to national grain security and whether people can live and work in peace and contentment. According to Table 3, Tfpch index values of key indexes of scientific and technological innovation in the pre-production stage of grain production of various cities of Henan Province during 2010-2019, Xinxiang, Puyang and Xinyang have Tfpch index greater than 1, which indicates that the total factor production rate of key input indicators of these three cities is at a good level and is on the rise. The increase of total factor productivity in Xinxiang is mainly due to the improvement of technical efficiency, while that Puyang and Xinyang is due to technological progress. Among them, Effch, Techch and Tfpch in Puyang and Xinyang are all greater than or equal to 1 , which indicates that the key technological innovation input and the efficiency of grain production and output in this city are gradually optimized, and the grain production has reached a good state during this period. From 2010 to 2019, the Tfpch index values of the secondary indicators in Luoyang, Pingdingshan, Anyang, Hebi, Luohe, Sanmenxia, Nanyang and Zhoukou all increased. Among them, Effch and Techch in Anyang, Hebi, Luohe, Nanyang and Zhoukou are all greater than or equal to 1, which are the regions with effective efficiency. The growth of total factor productivity in Luoyang and Zhoukou mainly benefited from technological progress, the increase of Tfpch index in Pingdingshan and Sanmenxia was due to the increase of technical efficiency, while in 
Anyang, Hebi, Luohe and Nanyang are all caused by the co-growth of Effch index and Techch index. Among all Tfpch indexes, the secondary index Tfpch values of Xinyang City decreased obviously, decreased by $14.6 \%$, and the decline of technical efficiency was the main reason.

Table 4. Input-output efficiency of key index, secondary index and in-production indicators of scientific and technological innovation of grain production in Henan Province.

\begin{tabular}{|c|c|c|c|c|c|c|}
\hline \multirow{2}{*}{ Province and Cities } & \multicolumn{3}{|c|}{ Key Indicators } & \multicolumn{3}{|c|}{ Secondary Indicators } \\
\hline & Effch & Techch & Tfpch & Effch & Techch & Tfpch \\
\hline Zhengzhou & 0.979 & 0.984 & 0.964 & 1.005 & 0.971 & 0.976 \\
\hline Kaifeng & 1.000 & 0.958 & 0.958 & 0.999 & 0.957 & 0.956 \\
\hline Luoyang & 0.991 & 0.973 & 0.964 & 0.992 & 1.011 & 1.003 \\
\hline Pingdingshan & 0.988 & 0.953 & 0.942 & 1.014 & 0.957 & 0.970 \\
\hline Anyang & 0.996 & 0.962 & 0.958 & 1.023 & 0.977 & 0.999 \\
\hline Hebi & 0.979 & 0.961 & 0.941 & 1.079 & 0.972 & 1.049 \\
\hline Xinxiang & 1.000 & 0.965 & 0.965 & 0.998 & 0.969 & 0.968 \\
\hline Jiaozuo & 0.987 & 0.976 & 0.963 & 0.999 & 0.970 & 0.969 \\
\hline Puyang & 1.000 & 0.994 & 0.994 & 1.030 & 0.953 & 0.982 \\
\hline Xuchang & 0.950 & 0.965 & 0.917 & 0.952 & 0.986 & 0.939 \\
\hline Luohe & 1.000 & 0.978 & 0.978 & 1.062 & 0.943 & 1.001 \\
\hline Sanmenxia & 1.013 & 0.898 & 0.910 & 1.171 & 0.898 & 1.051 \\
\hline Nanyang & 1.000 & 0.941 & 0.941 & 1.000 & 1.033 & 1.035 \\
\hline Shangqiu & 1.000 & 0.917 & 0.917 & 1.000 & 0.976 & 0.976 \\
\hline Xinyang & 1.000 & 1.017 & 1.017 & 0.966 & 0.884 & 0.854 \\
\hline Zhoukou & 1.000 & 0.957 & 0.957 & 1.000 & 1.014 & 1.014 \\
\hline Zhumadian & 1.000 & 0.918 & 0.918 & 1.000 & 0.930 & 0.930 \\
\hline Jiyuan & 0.983 & 0.960 & 0.944 & 0.993 & 0.958 & 0.951 \\
\hline Henan & 1.000 & 0.936 & 0.936 & 1.000 & 1.002 & 1.002 \\
\hline Mean & 0.993 & 0.958 & 0.951 & 1.014 & 0.958 & 0.971 \\
\hline
\end{tabular}

Table 5. Input-output efficiency of key indicators, secondary indicators and post-production indicators of scientific and technological innovation of grain production in Henan Province.

\begin{tabular}{|c|c|c|c|c|c|c|}
\hline \multirow{2}{*}{ Province and Cities } & \multicolumn{3}{|c|}{ Key Indicators } & \multicolumn{3}{|c|}{ Secondary Indicators } \\
\hline & Effch & Techch & Tfpch & Effch & Techch & Tfpch \\
\hline Zhengzhou & 1.005 & 0.971 & 0.976 & 1.027 & 1.097 & 1.126 \\
\hline Kaifeng & 0.999 & 0.957 & 0.956 & 1.010 & 1.039 & 1.049 \\
\hline Luoyang & 0.992 & 1.011 & 1.003 & 1.004 & 1.110 & 1.115 \\
\hline Pingdingshan & 1.014 & 0.957 & 0.970 & 1.033 & 1.044 & 1.078 \\
\hline Anyang & 1.023 & 0.977 & 0.999 & 1.056 & 1.055 & 1.114 \\
\hline Hebi & 1.079 & 0.972 & 1.049 & 1.000 & 1.111 & 1.111 \\
\hline Xinxiang & 0.998 & 0.969 & 0.968 & 0.995 & 1.065 & 1.060 \\
\hline Jiaozuo & 0.999 & 0.970 & 0.969 & 0.938 & 1.084 & 1.017 \\
\hline Puyang & 1.030 & 0.953 & 0.982 & 1.054 & 1.044 & 1.101 \\
\hline Xuchang & 0.952 & 0.986 & 0.939 & 1.016 & 1.107 & 1.125 \\
\hline Luohe & 1.062 & 0.943 & 1.001 & 1.037 & 1.022 & 1.060 \\
\hline Sanmenxia & 1.171 & 0.898 & 1.051 & 1.090 & 0.988 & 1.077 \\
\hline Nanyang & 1.000 & 0.976 & 0.976 & 1.079 & 1.120 & 1.208 \\
\hline Shangqiu & 1.000 & 0.879 & 0.879 & 1.000 & 1.016 & 1.016 \\
\hline Xinyang & 0.966 & 0.884 & 0.854 & 0.944 & 0.961 & 0.907 \\
\hline Zhoukou & 1.000 & 1.014 & 1.014 & 1.000 & 1.106 & 1.106 \\
\hline Zhumadian & 1.000 & 0.930 & 0.930 & 1.000 & 1.026 & 1.026 \\
\hline Jiyuan & 0.993 & 0.958 & 0.951 & 0.995 & 1.026 & 1.022 \\
\hline Henan & 1.000 & 1.002 & 1.002 & 1.000 & 1.002 & 1.081 \\
\hline Mean & 1.014 & 0.958 & 0.971 & 1.014 & 1.057 & 1.072 \\
\hline
\end{tabular}

On the whole, during the period from 2010 to 2019, the overall efficiency of key index input and secondary index input and output increased to some extent in 3 and 8 regions 
respectively, and the total factor productivity of secondary indicators was much higher than that of key indicators, which indicated that the total factor productivity of pre-production secondary indicators in Henan Province showed an upward trend. Therefore, the overall technical efficiency of the pre-production stage in Henan Province is not high, and each city should strengthen the utilization efficiency of key indicators in the pre-production stage. Among them, cities with effch less than 1 and techch greater than 1 should focus on optimizing the allocation of input elements to improve technical efficiency. For cities with effch greater than 1 and techch less than 1 , it should change the traditional breeding mode, take biological breeding technology as the core, through breeding technologies such as molecular technology and genetic engineering technology, deeply explore agricultural genetic resources, effectively utilize germplasm innovation. Improve prenatal pure technical efficiency and scale efficiency, and accelerate technological progress. At the same time, cooperation and exchanges with other provinces and cities should be strengthened, and introduce new varieties and technologies. As the aim is improve the efficiency of scientific and technological innovation in the pre-production stage of grain production.

Cultivation techniques matched with improved varieties can provide technical support for realizing grain security, stable production and increase production, saving costs and increasing efficiency. Under the situation of rigid growth of grain demand and constraints of cultivated land, water and other resources, it is also a particularly important technical means to give full play to the yield potential of grain varieties through cultivation and management measures in mid-production links. From Table 4, Tfpch index values of key indicators of technology innovation of the in-production stage of grain production in cities of Henan Province in 2010-2019, only Xinyang City's Tfpch index is greater than 1, the main reason for the increase is technological progress. It also shows that at this stage, the overall efficiency of input-output of key indicators in Xinyang City is constantly improving. However, the number of decision-making units with Tfpch index greater than 1 in this production stage is less than that in pre-production. In 2010-2019, among the Tfpch index values of secondary indicators greater than 1, there are Luoyang, Hebi, Luohe, Sanmenxia, Nanyang and Zhoukou, indicating that the overall efficiency of input-output of secondary factors in in-production stage of these six cities had been improved. Among them, the growth of Tfpch in Luoyang, Nanyang and Zhoukou mainly benefited from technological progress, the increase of Tfpch index in Hebi, Luohe and Sanmenxia was due to the increase of technical efficiency. Among all the Tfpch indexes, the secondary index Tfpch values of Xinyang City decreased the most obviously in 2010-2019, with a decrease of $14.6 \%$, which was mainly due to the decrease of technical efficiency, with a decrease of $11.6 \%$.

In general, the number of decision-making units with value of secondary index Tfpch greater than 1 is more than that of the key indicators, which indicates that Tfpch of preproduction secondary indicators in Henan Province is on the rise, but the number of decision-making units with Tfpch value greater than 1 of key indicators and secondary indicators is less than that of pre-production, which indicates that the technical efficiency in the in-production stage of grain production in Henan Province is lower than that preproduction. And on the whole, the technological progress of every city in Henan Province in grain production needs to be improved. Therefore, when developing agricultural scientific and technological innovation, Henan Province should pay more attention to the technical progress of key indicators in the in-production of grain production. By means of modern information technology, Internet of Things and other technologies, an intelligent field management system can be established. And by analyzing the reasonable growth conditions in different periods of grain production, personalized and intelligent production paths such as precise sowing, effective irrigation and precise fertilization can be formulated according to local conditions. For example, according to the characteristics of soil potassium deficiency in parts of Eastern Henan and zinc deficiency in parts of Western Henan, soil testing and formula fertilization should be carried out in different areas. And targeted and flexible irrigation should be carried out according to the characteristics of irrigation habits and seasonal water shortage in different areas. Thereby improving the precision of field 
management technology and the integration of agricultural machinery and agronomy, and realizing the technological innovation in the in-production.

Agricultural mechanization, as the carrier of modern agricultural scientific and technology innovation, is an advanced productive force in agricultural production. Mechanized harvesting technology is an important link in the whole process of mechanization, and post-production technologies such as intelligent harvesting technology, mechanized grain saving and loss reduction technology and information grain storage technology are also important technologies to ensure grain yield and quality. According to the Tfpch index values of key indicators of grain production technology innovation in Henan Province from 2010 to 2019, the Tfpch index of Luoyang, Hebi, Luohe, Sanmenxia and Zhoukou is greater than 1. It shows that during 2010-2019, the overall input-output efficiency of key indicators in these five cities has been improved to a certain extent. In this production stage, the number of decision-making units with Tfpch index greater than 1 is more than that in pre-production and in-production. The main reason for the increase in Luoyang and Zhoukou is technological progress, the increase of Tfpch index in Hebi, Luohe and Sanmenxia was due to the increase of technical efficiency. In 2010-2019, except Xinyang City, the Tfpch index values of secondary indicators of other cities are greater than 1 , which shows that the overall efficiency of secondary factor input-output of other cities in Henan Province has been improved. Among them, the total factor productivity growth of Hebi, Xinxiang, Jiaozuo, Shangqiu, Zhoukou, Zhumadian and Jiyuan mainly benefited from technological progress. The Tfpch index growth of other cities was caused by the co-growth of Effch index and Techch index. Among all the Tfpch indexes, the key indexes of Shangqiu and Xinyang City decreased most obviously from 2010 to 2019. The reason for the decline of Tfpch index in Shangqiu and Xinyang Cities is the decrease of technological progress, which is $3.4 \%$ and $11.6 \%$ respectively.

In general, the number of decision-making units with value of secondary index Tfpch greater than 1 is more than that of key indicators. The Tfpch values of secondary indicators in-production in Henan Province are on the rise, and the number of decision-making units with Tfpch values greater than 1 of key indicators and secondary indicators is more than that of pre-production and in-production. It shows that the technical efficiency of post-production in Henan Province is higher than that of pre-production and in-production, but the technical efficiency of key indicators still needs to be improved. Therefore, in order to improve the efficiency of post-production scientific and technological innovation, Henan Province should also strengthen the innovation of post-production technologies such as agricultural machinery and intelligent grain storage on the basis of guaranteeing the input of secondary indicators such as scientific and technological instruments and equipment. Realize the intelligentization of agricultural machinery and equipment such as intelligent yield measurement, joint harvest and green ecological grain storage with good quality, and improve the research and development level of post-production technologies such as harvesting technology and storage technology. Especially in cities with Effch less than 1 and Techch less than 1, it is necessary not only to increase the innovation and investment of agricultural technology in post-production and improve the technical level, but also to actively promote technological achievements and actively explore different forms of development, which is expected to promote the improvement of input-output rate through the improvement of technical efficiency. 
Based on the average value of Tfpch in the pre-production, in-production and postproduction stages of scientific and technological innovation of grain production in each city of Henan Province from 2010 to 2019 (as shown in Figure 3), there is an irregular "High-Low" development trend of scientific and technological innovation activities in the three stages of pre-production, in-production and post-production, but on the whole, the Tfpch of post-production is higher than that of the other two stages. At the same time, in 2010-2019, according to the main reason for the change of total factor productivity in various production stages of cities in Henan Province, technological progress plays a leading role, and the input-output efficiency of secondary indicators is higher than that of key indicators. The main reason for the improvement of secondary indicators and the input-output efficiency of each stage of grain production is that with the implementation of the policy of "storing grain in technology" in Henan Province. The input of secondary indicators has been continuously improved, and the innovation environment of production technology has been guaranteed. Some cities have filled the technical gap of germplasm resources innovation, improved seed cultivation and agricultural mechanization to a certain extent, while the key indicators with the number of R\&D institutions as the main factor have low input-output efficiency with prenatal indicators due to their long cycle and high cost. Therefore, in the development of grain production, every city in Henan Province should pay attention to the technological innovation and integration of preproduction, in-production and post-production to promote the collaborative innovation of grain production, and at the same time pay attention to the input efficiency of key indicators such as scientific and technological funds, so as to add impetus to scientific and technological innovation and provide basic guarantee for technological progress and achievement transformation. First of all, Henan Province should innovate and integrate a series of grain-increasing technical systems with high technical content and strong adaptability. At the same time, the technical efficiency of grain production cannot be improved without technical popularization. The government should guide scientific research projects to carry out experimental demonstrations in functional areas of grain production, entrepreneurial parks, science and technology parks and modern agricultural industrial parks, so as to promote the research and development of projects, promote the integration of scientific and technological achievements with industries. And establish a professional team for transforming scientific and technological achievements of grain, carry out grass-roots technical popularization services in depth. Open up the "last mile" for transforming scientific and technological achievements into agricultural productivity, implement scientific and technological innovation in every link of grain production, and realize the positive feedback of scientific and technological innovation in every link of grain production. Secondly, Henan Province should integrate internal and external resources for collaborative innovation, establish a mechanism of multi-source input and policy assistance, and innovate the transformation mechanism of scientific and technological achievements. It can promote the cooperation between universities and agricultural research institutes in personnel training, scientific research and resource sharing, and promote the active exertion of resource accumulation effect. It can improve the allocation efficiency and utilization rate of scientific and technological resources in order to establish a scientific and technological innovation platform for grain production in Henan Province and promote the communication and cooperation among scientific and technological research teams in various cities in Henan Province, thus realizing the effective integration of resources and the efficient transformation of scientific and technological achievements, and providing a good environment for improving the scientific and technological innovation efficiency of grain production. Realizing scientific and technological innovation and progress drives the substantial change of grain from traditional production mode to modern production mode. 


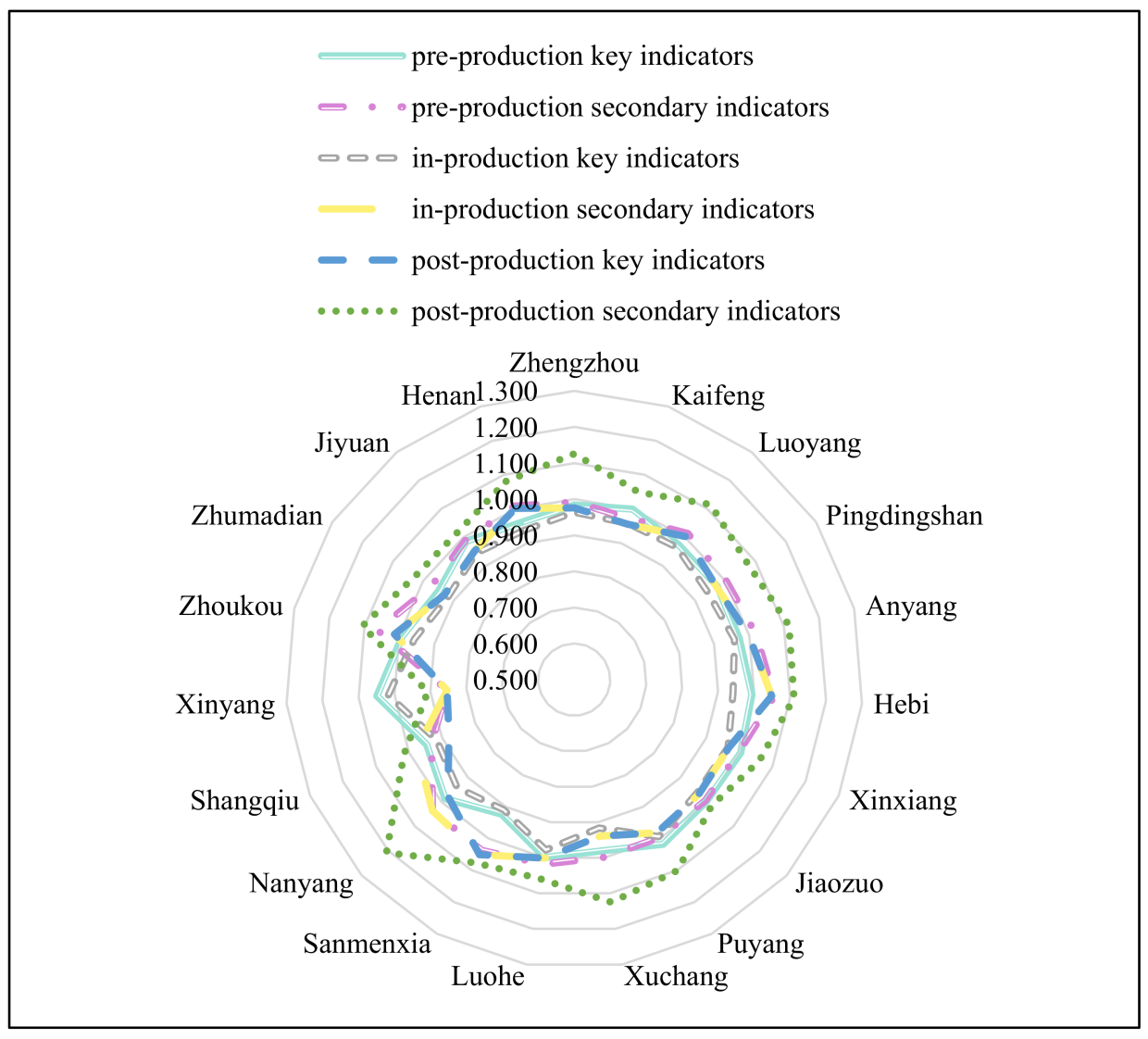

Figure 3. Trend of scientific and technological innovation efficiency in different stages of grain production in Henan Province.

\section{Conclusions}

This paper analyzes the efficiency of scientific and technological innovation of grain production in Henan Province, and constructs the index system of scientific and technological innovation of grain production based on the statistical data from 2010 to 2019. In the first step, we selected the grey absolute incidence analysis and grey relative incidence analysis which are suitable for this study, and improved the grey comprehensive incidence analysis model based on the idea of linear programming. Through the improved grey incidence model, the key and secondary factors that affect the grain output were screened. It is found that the type of basic ability of scientific and technological innovation indicators and transformation ability of scientific and technological achievements are the main indexes categories that affect grain output. This is highly consistent with the conclusion of most researchers that "agricultural science and technology innovation is the main driving force to promote agricultural development [42-44], and the transformation of scientific and technological achievements is an important factor affecting grain production efficiency [45-48]". It also shows that increasing the input of the investment of basic resources of scientific and technological innovation, effective allocation of resources, accelerating scientific and technological innovation and improving transformation rate of scientific and technological achievements are crucial for improving grain outputs and ensuring grain security.

The second step, in order to deeply explore the production efficiency of scientific and technological innovation and grain production, this paper took the grain production process as the object, divided the indicators of scientific and technological achievements transformation into pre-production, in-production and post-production stages, and analyzed the scientific and technological innovation efficiency of key indicators and secondary indicators in each stage of grain production based on DEA-Malmquist index model. The results show that compared with other production stages, the total factor productivity 
of the post-production stage has a certain degree of improvement, showing an upward trend. On the whole, the total factor productivity of the secondary indicators in the preproduction, in-production and post-production of grain production in Henan Province shows an upward trend, while the total factor productivity of the key indicators shows a downward trend. From the internal cause of the gap between the grain production stages and the total factor production of scientific and technological innovation index in Henan Province, there is a gap between various types of input factors and technological innovation performance of grain production in Henan Province, and the technological progress index is the leading factor. Similarly, this research result echoes the conclusion that "technological progress is the leading factor to promote agricultural total factor productivity" drawn by Peng et al. [49].

Therefore, we should pay attention to the development of scientific and technological progress of the pre-production and in-production stages, strengthen the input of scientific and technological innovation foundation, reasonably plan resource allocation and improve the transformation of scientific and technological innovation achievements, promote the exchange of scientific and technological innovation activities of grain production among cities in Henan Province. It is essential to improve the overall technical level, competitiveness and system innovation ability, so as to promote the development of scientific and technological innovation in grain production, and provide guarantee for grain security.

In this study, an improved grey incidence model was established, and a deep analysis of the efficiency of scientific and technological innovation of grain production in Henan Province was carried out by stages of production and key indicators and secondary indicators, which provided technical support and ideas for the research of scientific and technological innovation efficiency of grain production. However, there are still some shortcomings in this study. For example, the index system of scientific and technological innovation in grain production established in this paper is quantitative without adding qualitative indicators. Therefore, the efficiency of scientific and technological innovation in grain production can be further studied, so as to further analyze the efficiency of scientific and technological innovation in each stage of grain production. And whether the selection of indicators can be further refined while ensuring the accuracy of data will be the direction of further research in the future.

Author Contributions: Writing—original draft, S.Z.; Writing—review \& editing, B.L. and Y.Y. All authors have read and agreed to the published version of the manuscript.

Funding: This research was funded by the Soft-science Foundation of Henan Provincial Research Key Project, grant number: 202400410051 and the joint research grant of Royal Society and National Science Foundation of China, grant number: IEC $\backslash N S F C \backslash 170391$.

Conflicts of Interest: The authors declare no conflict of interest.

\section{References}

1. Li, B.J.; Zhang, S.H. Multidimensional research on agrometeorological disasters based on grey BP neural network. Grey Syst. Theor. Appl. 2021, 11, 537-555. [CrossRef]

2. Yang, C.X.; Zhang, J.B.; Zhao, K. An empirical research on the relationship between agricultural science and technology resources and economic development of agriculture. China Popul. Resour. Environ. 2011, 21, 113-118.

3. Mengui, K.C.; Oh, S.; Lee, S.H. The technical efficiency of smallholder Irish potato producers in Santa subdivision, Cameroon. Agriculture 2019, 9, 259. [CrossRef]

4. Li, H.F. Regional Difference Analysis of Agricultural Technology Production Efficiency in China Based on Data Envelopment Analysis. Sci. Tech. Manag. Res. 2020, 40, 59-66.

5. Yang, Z.H.; Wang, D.; Du, T.Y.; Zhang, A.L.; Zhou, Y.X. Total-factor energy efficiency in China's agricultural sector: Trends, disparities and potentials. Energies 2018, 11, 853. [CrossRef]

6. Headey, D.; Alauddin, M.; Rao, D.S.P. Explaining agricultural productivity growth: An international perspective. Agric. Econ. 2010, 41, 1-14. [CrossRef]

7. Jalilov, S.-M.; Mainuddin, M.; Maniruzzaman, M.; Mahbubul Alam, M.; Towfiqul Islam, M.; Jahangir Kabir, M. Efficiency in the Rice Farming: Evidence from Northwest Bangladesh. Agriculture 2019, 9, 245. [CrossRef] 
8. Tang, J.; Jose, V. Research on technical efficiency of grain production and influencing factors: Based on panel data of 31 provinces in China from 1990 to 2013. J. Agrotech. Econ. 2016, 9, 72-83.

9. Zheng, S.F.; Mou, X.R.; Zhang, Z.Z. Analysis on the production efficiency and restriction factors of Chinese rice based on DEA model. J. Discret. Math. Sci. Crypt. 2018, 21, 1215-1218. [CrossRef]

10. Shen, Q.; Wang, S.P.; Zhang, S.R. Impact of agricultural technological innovation on grain production efficiency. J. Agro-Fores. Econ. Manag. 2018, 17, 669-677.

11. Zayats, L.K.; Samsonovich, V.A. Stages of the development of agricultural production in the republic of Belarus: To the 100th anniversary of the ministry of agriculture and food of the republic of Belarus. Proc. Natl. Aca. Sci. USA 2019, 57, 7-18. [CrossRef]

12. Chen, M.; Ma, L.; Che, X.; Dou, H. Identification of transformation stages and evolution of agricultural development types based on total factor productivity analysis: A case study of Gansu province, China. Agriculture 2020, 10, 363. [CrossRef]

13. Shi, M.; Paudel, K.P.; Chen, F.B. Mechanization and efficiency in rice production in China. J. Integr. Agric. 2021, 20, 1996-2008. [CrossRef]

14. Jiang, S.; Wang, Z.; Huang, Q.H.; Zhou, Z.B.; Chen, X.D. Research on the speed and contribution of scientific and technological progress in grain production: Based on provincial panel data from 1985 to 2010. J. Agrotech. Econ. 2012, 10, 40-51.

15. Wang, W.; Guo, L.W. Sources of production growth in Chinese agriculture:empirical evidence from penal data results 2001-2018. Appl. Econ. 2021, 53, 5135-5157. [CrossRef]

16. Yang, Z.H.; Lei, L.H.; Yue, G.N.; Yao, Z.F. Promotion effects of agricultural research and development expenditure and science and technology innovation on agricultural production. J. South Agric. 2019, 50, 2855-2864.

17. Zhao, L.J.; Zhang, Y.X.; Pan, F.H. Government R\&D inputs, environmental regulation and efficiency of agricultural S\&T innovation. Sci. Res. Manag. 2019, 40, 76-85.

18. Mao, S.P.; Yang, Y.L.; Lin, Q.N. The evolution and effect of chinese agricultural science and technology innovation policies since reform and opening up: Empirical data analysis from chinese agricultural research institutions. Issues Agric. Econ. 2019, 1, 73-85.

19. Lissitsa, A.; Odening, M. Efficiency and total factor productivity in Ukrainian agriculture in transition. Agric. Econ. 2005, 32, 311-325. [CrossRef]

20. Li, H.R.; Mao, L.L.; Mei, X.R.; Liu, Y.E.; Hao, W.P. Analysis on influencing factors of grain production fluctuation during the last 30 years in China. Chin. J. Agric. Res. Reg. Plan. 2018, 39, 1-10, 16.

21. Liu, H.F.; Liu, H.L. Measurement and evaluation of technological innovation of 'Resource-saving and Environment-friendly' agriculture: Based on gray correlation analysis. J. Hunan Univ. Sci. Tech. 2014, 17, 102-110.

22. Dong, F.; Qi, B.; Jie, Y. Comparative static analysis of provincial agricultural science and technology level based on grey clustering. Grey Syst. Theor. Appl. 2018, 8, 481-493. [CrossRef]

23. He, Z.J.; Li, Y. Analysis on change characteristics of agricultural total factor productivityin China based on the method of DEA-Malmquist index. J. Henan Agric. Univer. 2018, 52, 839-844.

24. Zhao, Y.Z.; Jiang, Q.X.; Wang, Z.L. The system evaluation of grain production efficiency and analysis of driving factors in Heilongjiang Province. Water 2019, 11, 1073. [CrossRef]

25. Zheng, Z.X.; Sun, Z.Y.; Lin, L. Agricultural technological progress, scale efficiency and food security: A case of japonica rice and corn in the three provinces of Northeast China. Resour. Dev. Market. 2021, in press.

26. Bro, R.; Smilde, A.K. Principal component analysis. Anal. Methods 2014, 6, 2812-2831. [CrossRef]

27. Dinno, A. Implementing Horn's parallel analysis for principal component analysis and factor analysis. Stata J. 2009, 9 , 291-298. [CrossRef]

28. Liu, S.F.; Fang, Z.G.; Xie, N.M.; Dang, Y.G.; Zeng, B.; Guo, Y.C. Theory and Application of Grey System, 8th ed.; Science Press: Beijing, China, 2018; pp. 55-73.

29. Zhang, R.; Liu, B.; Li, Y.; Dong, F.Y. A New Computation Model of Grey Relational Degree. J. Grey Syst. 2011, $23,161-168$.

30. Huang, X.X.; Liu, S.F.; Tani, X.R. An Improved Test Method for Grey Relational Order. J. Grey Syst. 2017, $29,64-77$.

31. Wen, K.L. The proof of a new modified grey relational grade. Grey Syst. Theor. Appl. 2016, 6, 180-186. [CrossRef]

32. Wu, Y.; Lei, J.W.; Bao, L.S.; Li, C.Z. Short-term load forecasting based on improved grey relational analysis and neural network optimized by bat algorithm. Auto. Elec. Power Syst. 2018, 42, 67-72.

33. He, J.; Li, S.H.; Zhou, Z.P.; Xing, Z.C. Evaluation of radar anti-jamming ability based on game theory and grey relation analysis. Fire Cont. Command. Cont. 2014, 39, 119-122.

34. Yan, G.L.; Zhang, Y.; Liu, Y.L. Systems Engineering; China Machine Press: Beijing, China, 2008.

35. Zhou, S.D. Management, 4th ed.; Higher Education Press: Beijing, China, 2014.

36. Yang, Y. Analysis of weighting method in multi-index comprehensive evaluation. Stat Dec. 2006, 13, 17-19.

37. Behzadian, M.; Otaghsara, S.K.; Yazdani, M.; Ignatius, J. A state-of the-art survey of TOPSIS applications. Expert Syst. Appl. 2012, 39, 13051-13069. [CrossRef]

38. Dong, Y.H.; Fu, Z.T.; Peng, Y.Q.; Zheng, Y.J.; Yan, H.J. Precision fertilization method of field crops based on the Wavelet-BP neural network in China. J. Clean. Prod. 2020, 246, 118735. [CrossRef]

39. Zhang, S.H.; Huang, G.Y.; Zhang, Y.F.; Li, B.J. Screening of key grain production techniques based on grey relational analysis. J. Henan Agric. Univer. 2021, 55, 356-363.

40. Caves, D.W.; Christensen, L.R.; Diewert, W.E. Multilateral comparisons of output, input, and productivity using superlative index numbers. Econ. J. 1982, 92, 73-86. [CrossRef] 
41. Zhao, Q.S.; Pan, P.P.; Wang, X.X.; Wang, X.R.; Wang, X.M.; Li, N.; Wang, X.Y. A Study of cultivated land utilization efficiency and its influencing factors in Hebei Province based on DEA-Malamquist index. Arid Zone Res. 2021, 38, 1-12.

42. Tian, H.Y.; Zhu, Z.Y. Analysis of food production efficiency and its influencing factors in China: Verification based on MalmquistDEA and Tobit model. Chin. Agric. Res. Reg. Plan. 2018, 39, 161-168.

43. Geng, Y.N.; Liu, J. The threshold effect of labor migration and technological progress on grain yields. Econ. Prob. 2019, 12, 96-103

44. Wang, L.; Qi, Z.; Pang, Q.; Xiang, Y.B.; Sun, Y.L. Analysis on the agricultural green production efficiency and driving factors of urban agglomerations in the middle reaches of the yangtze river. Sustainability 2021, 13, 97. [CrossRef]

45. Cheng, C.P. Problems and countermeasures of agricultural scientific and technological innovation in China. Agric. Econ. 2017, $48,17-19$.

46. Wan, R.B. Science and technology: The fundamental way out for China's agriculture. Seek Truth 2012, $17,35-37$.

47. Yao, L.X.; Huang, J.P. Comparison of scientific and technological investment and innovation capabilities in Central China. Reform 2014, 6, 105-112.

48. Yang, T.B.; Zhu, Y.M.; Wang, Y. Land use intensification, technology progress and agricultural production efficiency. Agric. Econ. Manag. 2020, 1, 54-65.

49. Peng, L.; Su, C.; Sun, L.; Li, P.; Fang, Y.; Liu, W.; Wang, X. Spatial-temporal evolution pattern of agricultural productivity in northwestern sichuan plateau. J. Mt. Sci. 2013, 10, 418-427. [CrossRef] 